\title{
Sports injury registration: the Fysion Blesreg system
}

\author{
J. V. de Bruijn ${ }^{1}$ and S. Keizers ${ }^{2}$ \\ ${ }^{1}$ Sport Physiotherapist of the Dutch Handball Association, Fysion Advice Bureau Injury Prevention, Maarssen, \\ The Netherlands \\ 2 Pharmacist, Fysion Advice Bureau Injury Prevention, Maarssen, The Netherlands
}

Fysion Blesreg is a new system on which sports assistants (trainers, masseurs, physiotherapists and physicians) can rely for quick and straightforward registration and retrieval of personalized injury data. Registration of injury data can provide a clear picture of the injury mechanism, which in turn can lead to effective preventive measures and a decline in sports injuries.

The two components of the Fysion Blesreg system are registration forms and computer software. Registration forms are filled out when the competition starts (zero form), and when injuries occur (team cards and players' cards). Data are collected for the individual (zero form), the sports activity (team card), and the cause, nature and treatment of the injury (player's card). All data are entered into the computer with an MS-DOS based computer program, and can in various ways be reported or graphically reproduced.

Keywords: Injury registration, computer, analysing injury

Holland, with a population of $14.9 \mathrm{~m}$, has some $2.7 \mathrm{~m}$ cases of sports injuries every year ${ }^{1}$. Over $1.7 \mathrm{~m}$ cases receive medical attention. Most sports injuries involve the ankle $(23 \%)$ and the knee $(14 \%)$.

Prevention has become the focus of attention in the fight against sports injuries. Nationwide campaigns have been launched to inform the public and to promote the use of a warming-up period and a gradually built-up training schedule. With many possible causes of sports injuries, prevention remains a highly complex issue, and preventive measures cannot be taken before the main causes have been determined. Schlatmann refers to the 'prevention sequence', meaning the determination of causes through registration of injuries, after which specific measures can be taken to prevent similar injuries in future. The final step is to assess the effectiveness of such measures, also through registration ${ }^{2}$.

An early registration system was developed for the purpose of epidemic research by the National Institute for Health Care ${ }^{2}$. This involved registration of all internal and external factors which led to sports

Address for correspondence: J. V. de Bruijn, Zebraspoor 650, 3605 HL Maarssen, The Netherlands

(C) 1991 Butterworth-Heinemann Ltd.

0306-3674/91/030124-05 injury, together with its social and sports-related consequences. Another system, based on computerread forms, was developed predominantly for the classification of services performed by sports medicine consultants ${ }^{3}$.

In cooperation with several sports unions and organizations, the author has developed the Fysion Blesreg injury registration system. Its simplicity and minimal need for computers make it an ideal resource for all medical staff of sports clubs and organizations.

\section{Method}

The Fysion Blesreg system is designed for the registration of sports injuries. For proper use of this system, the terms 'sports injury' and 'sports activity' must first be defined (Council of Europe, 1988) ${ }^{4}$.

A sports injury is one which occurs as a result of participation in sport and has one or more of the following consequences:

- a reduction in the amount or level of sports activity

- need for advice or treatment

- adverse economic or social effect.

Sports activity is a period in which a player performs his or her sport during a certain time with a certain intensity.

The system involves the registration of both pre-injury data (personal and anthropometric) and data during and after injury (circumstances, nature, treatment, after-care).

The data are collected with three injury forms and a computer program. The printed injury forms are filled out immediately after the injury has occurred, possibly even before the player is taken off the field. Subsequently, all data are entered into the computer.

\section{Injury forms}

\section{The zero form}

The object of the zero form is to collect data on all players involved as an aid for interpretation of injury data. Details of personal data, training, and level of performance and experience in the particular branch of sports are collected at the start of the registration period, and when changes occur in the team (Figure 1). 


\section{Player number.}

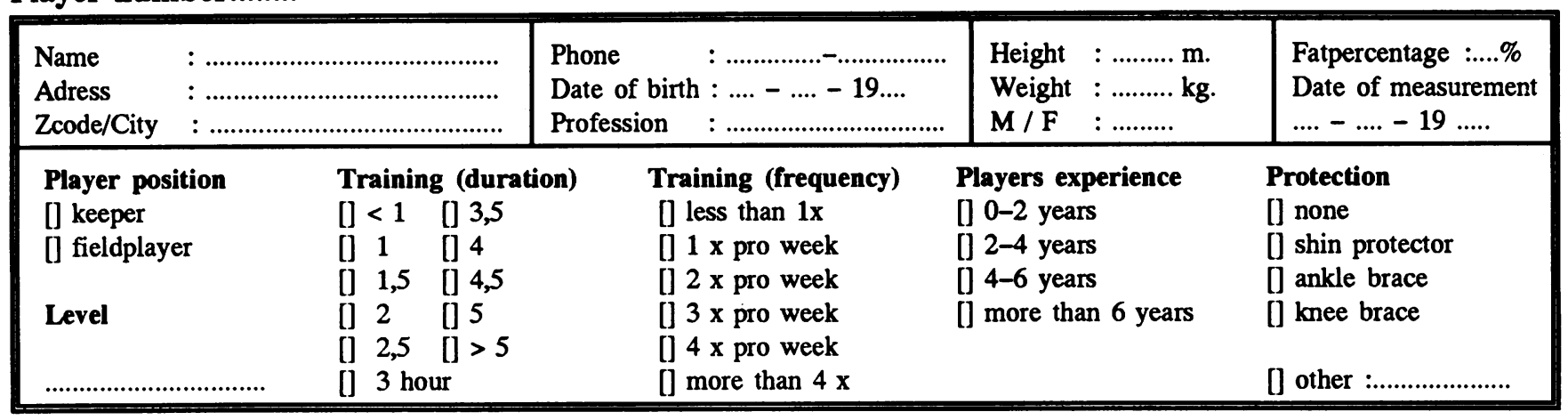

Figure 1 Fysion Blesreg injury card - zero form

Fysion Blesreg General (Team-card)

(C) 1991 Fysion Advice Bureau Injury Prevention Maarssen

\begin{tabular}{|c|c|c|c|c|}
\hline Team & $\begin{array}{l}\text { Event } \\
\text { [] practice } \\
\text { [] competitional match } \\
\text { [] trial match } \\
\text { [] selection match } \\
\text { [] cup match } \\
\text { [] tournament }\end{array}$ & $\begin{array}{l}\text { Date event } \\
\text { City } \\
\text { Opponent } \\
\text { Number of }\end{array}$ & 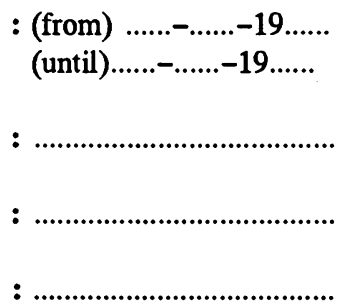 & $\begin{array}{l}\text { Assistance } \\
\text { [] (sport)physician } \\
\text { [] (sport)fysiotherapist } \\
\text { [] (sport)masseur } \\
\text { [] }\end{array}$ \\
\hline
\end{tabular}

Figure 2 Fysion Blesreg injury card - team card

\section{Team card}

The team card is always filled out whenever sports activities take place. Data registered include time, nature, attendance and circumstances of the sports activity (Figure 2).

\section{Player's card}

The player's card is filled out whenever injuries occur. Data registered here involve nature, cause, direct consequences, first aid and further treatment of the injury (Figure 3).

\section{Computer program}

With the Fysion Blesreg computer program, injury data can be stored in the computer. They can be retrieved, adjusted, removed, printed out or graphically reproduced whenever required (Figures 4,5 and 6).

The program requires IBM-compatible hardware programmed in MS-DOS, including a printer for printing out data and graphics and, optionally, a mouse. With its $350 \mathrm{~kb}$ memory the whole program is contained in one disk, but for maximal speed and memory the use of a hard disk is recommended. There are several safety checks on the entered data. For security purposes the computer is linked to a special key, and every user receives his or her own PIN code.

The Fysion Blesreg system is fully menu-operated. The program can therefore be used without having to enter any special commands. Through a large number of options one can select the function required (Figures $7,8,9$ and 10).

\section{Beneficiaries}

The Fysion Blesreg system is designed for all physical assistants in sports clubs and organizations. Coaches, masseurs, physiotherapists, physicians and managers are all likely to benefit from the many different aspects of this program.

The coach can compare causes of injury and draw his conclusions regarding training methods and competition level. He can discuss the information with his medical assistant and, if necessary, change his training schedule (course, intensity, frequency).

The medical assistant, usually a masseur or physiotherapist, can refer to the computer to assess a player's physical health. The information on the nature and the cause of the injury enables him to give first aid, provide for further treatment and take preventive measures for future injuries.

The physiotherapist or physician attending an injured player can base his therapy, consultation and evaluation on his knowledge of the circumstances in which the injury occurred. Also, if specialist help or first aid in hospital is needed, he can produce an injury card to help an accurate diagnosis and quick evaluation.

The Managing Board can obtain a clear picture of the number of injuries and assess the effectiveness of their policy on sports injuries.

The player receives optimal medical attention, since his attendant has all relevant information on his patient's medical history directly available and can base his treatment on this information. Even if the player's own attendant is absent, his replacement can quickly review the player's medical record and supply him with the best help. 


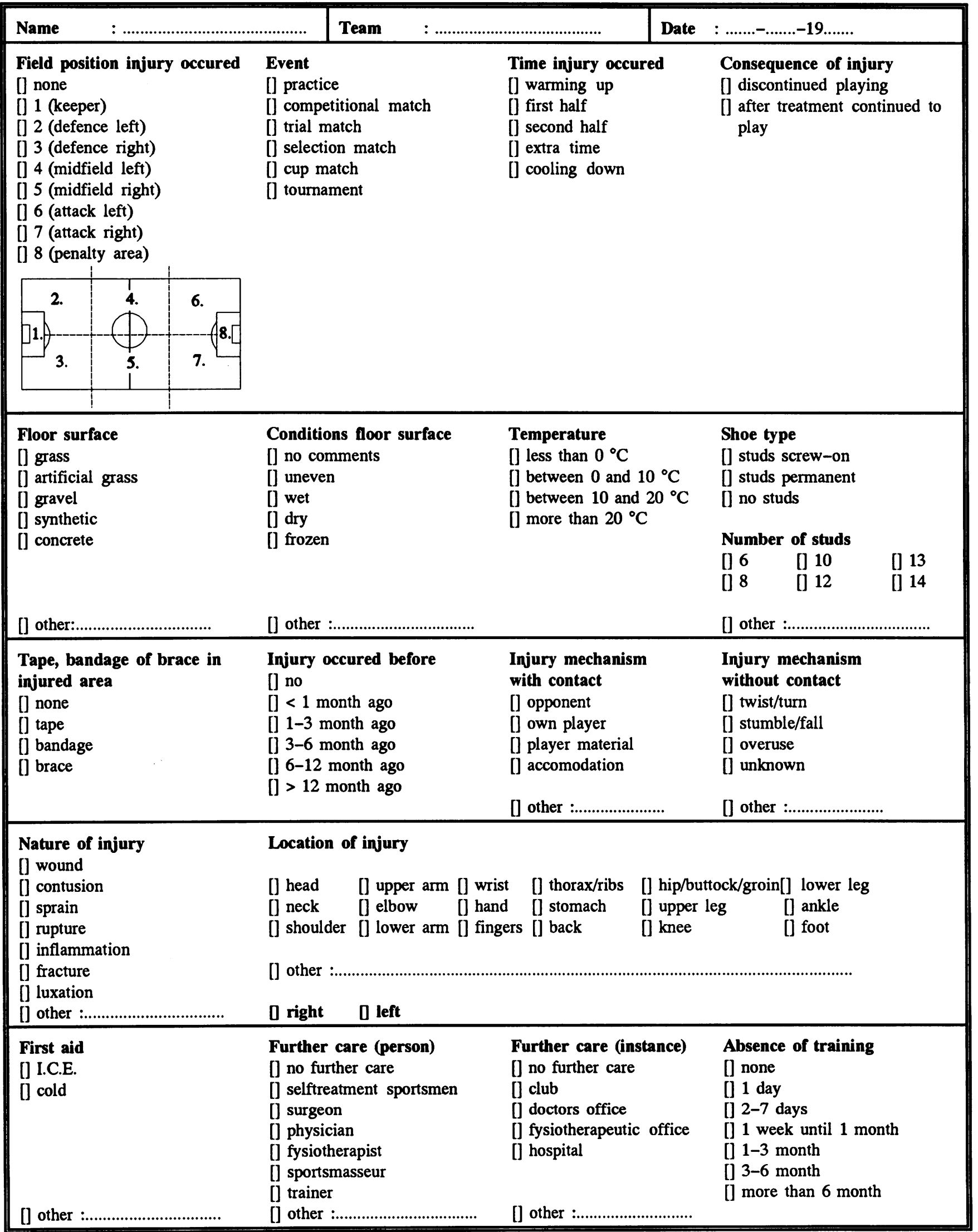

Figure 3 Fysion Blesreg injury card - player's card 
Sports injury registration: J. V. de Bruijn and S. Keizers

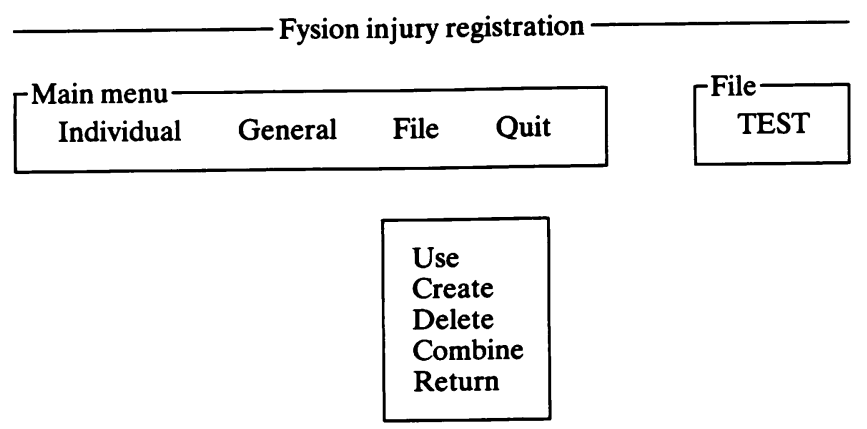

Figure 4 File-function of the computer program

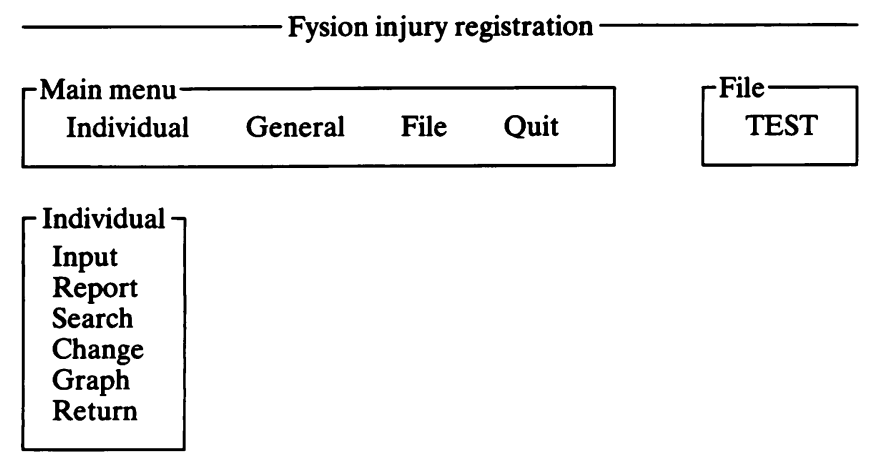

Figure 5 Available options when entering the individual card

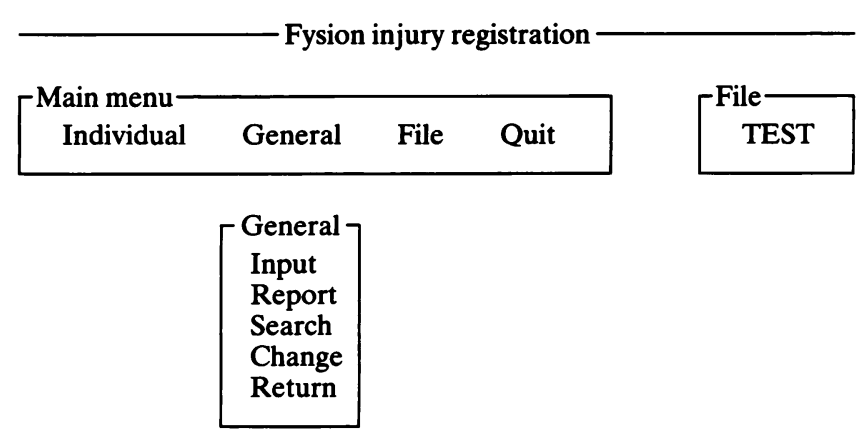

Figure 6 Available options when entering the general card

\begin{tabular}{|c|c|}
\hline$\Gamma$ General & \\
\hline Team .................... & $: \mathbf{A}$ \\
\hline Event $. . . \ldots \ldots \ldots \ldots . . . .$. & : Practice \\
\hline Date event (until) & : 28.06 .91 \\
\hline Date event (from) & : 28.06 .91 \\
\hline City event ............ & Amsterdam \\
\hline Opponent ............... & : None \\
\hline Number of injuries & 2 \\
\hline Assistance ........... & : Physiotherapist \\
\hline Name assistance ... & : J. V. de Bruijn \\
\hline Comments ........... & : Last training this season! \\
\hline
\end{tabular}

Figure 7 Data of the general form as displayed on the screen

\begin{tabular}{|l|l|}
\hline \multicolumn{2}{c}{ Fysion injury registration } \\
\hline \begin{tabular}{|l} 
Individual- Team: \\
Name: S. Keizers
\end{tabular} & \multicolumn{1}{c}{ Date: 28.06.91 } \\
\hline Field position & 1 (defence left) \\
Event & Discontinued playing \\
Direct consequence & Grass, dry \\
Floor surface & Between 10 and 20C \\
Environment temperature & No cluds \\
Shoe type & 6 \\
Number of cluds & No \\
Tape, bandage or brace & Yes, 6-12 months ago \\
Injury occurred before & Stumble/fall \\
Injury mechanism & Luxation \\
Nature of injury & Shoulder left \\
Location of injury & Bandage \\
First aid & Surgeon, hospital \\
Further care & $1-3$ month \\
Absence of training & \\
\hline
\end{tabular}

Figure 8 Data of the individual form as displayed on the screen

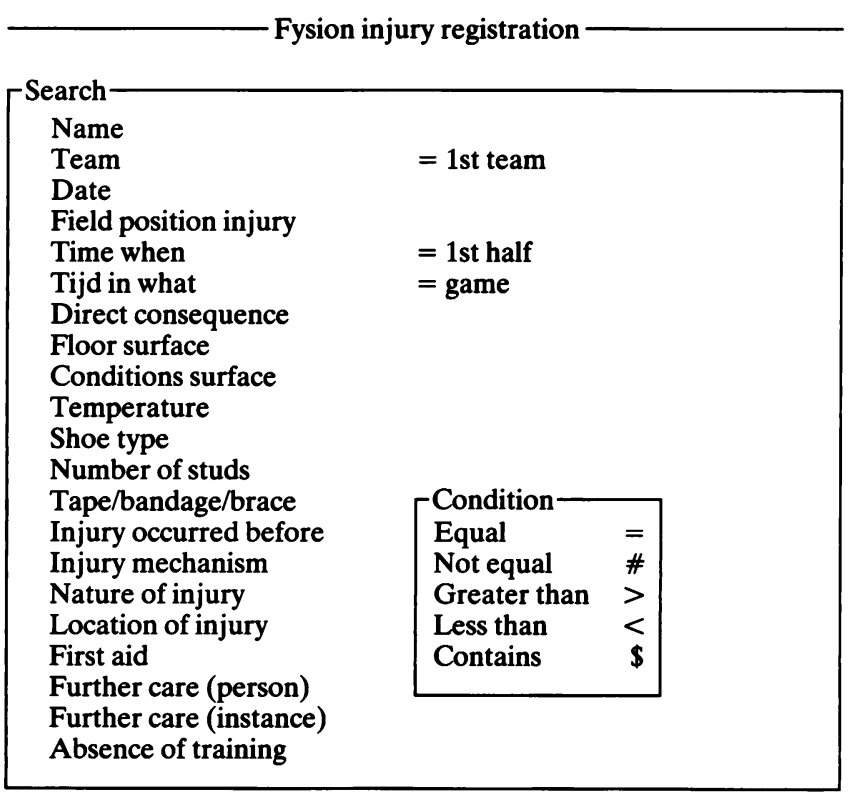

Figure 9 The search function as displayed on the screen

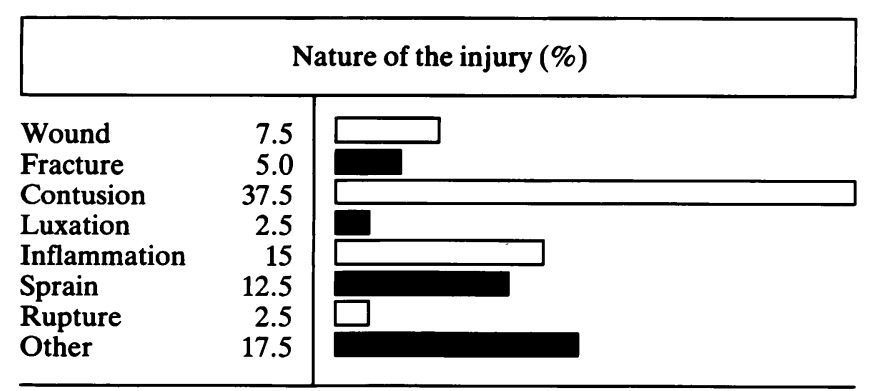

Figure 10. Graph function of the individual form. This graph shows the nature of the injury 


\section{Different versions}

In the first instance this system was designed for team sports. At this stage there are several different versions for soccer, handball, volleyball, korfball, hockey and basketball. Their distinctive features concern the player's position, floor surface and footwear. Since the basic principles remain the same, Fysion Blesreg can easily be transformed for all branches of sports.

\section{Prospects}

In the near future the existing versions will be further improved and extended. In cooperation with the sports unions new versions will be developed. Particular attention will be given to those sports where most injuries are due to excessive strain. Additionally, this registration system may find its way into the business and public sectors.

\section{Discussion}

To obtain unambiguous, reproducible injury registration, the various terms used must be strictly defined. Fysion Blesreg has, therefore, derived its definitions from the official Dutch guide on first aid, Het Oranje Kruis Boekje ${ }^{5}$. Thus, trainers and masseurs, physiotherapists and physicans can all make use of the system and interpret data others have entered. Determination of the nature of a sports injury, however, remains the task of experts, and most initial diagnoses will later be adjusted or confirmed by a physician or a first aid centre. Fysion Blesreg, therefore, includes an option to make additions or adjustments to data previously entered.
In this registration system the gravity of a sports injury must be judged from its nature and direct consequences. There are no data entered on presumed length of follow-up. This has deliberately been omitted, since the date of full recovery can only be established some time after the injury has occurred. Full recovery is a disputable concept. Has full recovery been achieved when the player can join the training sessions again, or does full recovery imply that he can play an entire match without needing braces or bandages? This is a matter for further discussion.

Fysion Blesreg is, in first instance, a registration program. Data can be reproduced in graphics. Their interpretation, however, and the drawing of conclusions remains a task for experts, since there is often multiple interaction of causes.

The Fysion Blesreg program costs fl.550 (first copy), fl.125 (additional copies) (approximately $£ 215$ and £38).

\section{References}

1 van Galen WChW, Diederiks JPM. Blessures Breed Uitgemeten. Haarlem: de Vrieseborch, 1990.

2 Schlatmann H, Hlobil H, van Mechelen W, Kemper HGC. Naar een reistratiesysteem van sportblessures in Nederland. Oosterbeek: NISGZ publikatie 26, 1986.

3 Beijer HJM, Backx FJG. Landelijke registratie van blessures op de Sportmedische Adviescentra in Nederland; Het registratieformulier. Geneeskunde en sport 1990; 23(1): 5-7.

4 Togt van der C. Sports for all; sports injuries and their prevention. Verslag van een project. Geneeshunde en Sport 1989; 22: $46-8$.

5 Oranje Kruis Boekje. Officiéle handleiding tet het verlenen van eerste hulp bý engeluhhen. Leiden: van Mantzem \& De Does bv, 1981. 